\title{
Review \\ The role of carbapenems in initial therapy for serious Gram-negative infections
}

\author{
James J Rahal ${ }^{1,2}$ \\ ${ }^{1}$ Infections Disease Section, New York Hospital Queens, 56-95 Main Street, Flushing, NY 11355, USA \\ ${ }^{2}$ Weill Cornell Medical College, 425 East 61st Street, New York, NY 10021, USA
}

Corresponding author: James J Rahal, JJR9002@nyp.org

Published: 21 May 2008

Critical Care 2008, 12(Suppl 4):S5 (doi:10.1186/cc6821)

This article is online at http://ccforum.com/content/12/S4/S5

(c) 2008 BioMed Central Ltd

\begin{abstract}
The treatment of patients with serious Gram-negative infections must be both prompt and correct. Numerous studies have demonstrated that mortality risk is significantly increased when the initial antibiotic regimen does not adequately cover the infecting pathogen. Furthermore, changing to an appropriate regimen once culture results are available does not reduce this risk. Therefore, one must empirically treat serious infections with a regimen that covers likely pathogens. Selecting such a regimen is complicated by the increasing prevalence of resistance to commonly used antibiotics. Moreover, multidrug-resistant pathogens, once limited to hospital-acquired infections, are increasingly being detected in community-acquired infections, especially those involving the urinary and gastrointestinal tracts or in immunocompromised patients. Consequently, the initial antibiotic regimen must have a broad spectrum of activity that includes potential resistant pathogens, as indicated by the local antibiogram. Many multidrugresistant pathogens remain susceptible to carbapenems despite increasing worldwide antibiotic resistance. This article reviews the role played by carbapenems in the initial treatment of serious Gram-negative infections and the potential effect of emerging resistance on this role.
\end{abstract}

\section{Introduction}

Appropriate antibiotic therapy for any given circumstance requires consideration of three factors: the pathogen, the timing, and the patient, including the site of infection. The role of the pathogen is clearly understood. Treatment must be directed at the pathogens potentially responsible for the patient's illness, and this treatment must take into consideration local resistance factors for these pathogens. In serious bacterial infections such as bacteremia and ventilatorassociated pneumonia (VAP), antibiotic resistance is the most important risk factor for therapeutic failure [1,2]. In a prospective, multicenter evaluation [2], 19\% of Klebsiella pneumoniae bacteremias were caused by organisms that produced extended-spectrum $\beta$-lactamase (ESBL). Twenty- four per cent of these patients died within 14 days of the first positive blood culture. The single greatest risk factor for mortality was failure to use an antibiotic with in vitro activity against the isolate during the initial 5 days (odds ratio 10.7, $95 \%$ confidence interval 2.2 to $57.0 ; P=0.001$ ).

Although less often appreciated than the pathogen, the significance of therapeutic timing is equally important. In the study described above, reduced mortality was associated not only with appropriate antimicrobial therapy but also with the initiation of this therapy early in the course of the disease process. Likewise, several evaluations of both VAP (Figure 1) [3-6] and septicemia (Figure 2) [7-10] have demonstrated that inadequate initial antibiotic therapy was associated with increased mortality risk. In one evaluation [11], 73\% of patients with VAP received an initial empiric antibiotic regimen that was inappropriate for their infection based on subsequent culture results. In multivariate analysis, this inappropriate antibiotic selection was a significant and independent risk factor for in-hospital mortality (odds ratio $3.28,95 \%$ confidence interval 2.12 to $5.06 ; P=0.006)$. In another evaluation of patients with VAP [5], inappropriate initial antibiotic therapy was associated with a 2.4-fold increase in mortality risk (95\% confidence interval 1.5-fold to 5.0-fold). Furthermore, changing from inappropriate to appropriate therapy once culture results were available did not reduce this risk significantly. Consequently, in order to reduce mortality, it is essential that the initial antibiotic regimen appropriately cover likely pathogens [8,12]. Therefore, the initial 12 to 24 hours of therapy is not a time to be concerned with restricting antibiotics.

Patient status also influences the prognosis and therefore the treatment approach. Patients with prolonged hospitalization, prior antibiotic use, or higher Acute Physiology and Chronic

$\mathrm{ESBL}=$ extended-spectrum $\beta$-lactamase $; \mathrm{KBC}=$ Klebsiella pneumoniae carbapenemase; $\mathrm{MDR}=$ multidrug-resistant; $\mathrm{VAP}=$ ventilator-associated pneumonia. 


\section{Figure 1}

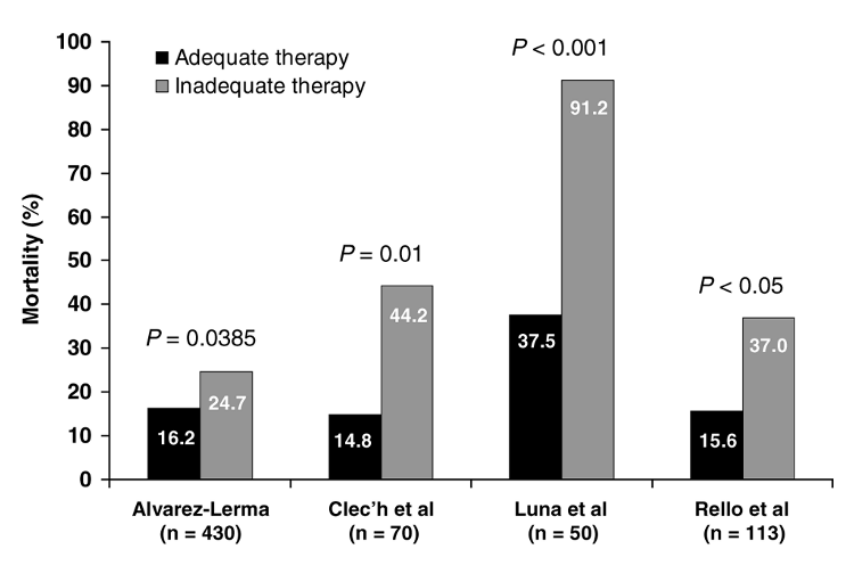

Adequate versus inadequate initial antibiotic therapy: intensive care unit (ICU)-acquired pneumonia and ventilator-associated pneumonia (VAP). Shown is the mortality risk associated with adequate versus inadequate initial antibiotic therapy in patients with ICU-acquired pneumonia [3] or VAP [4-6].

Health Evaluation II scores are more likely to be infected with resistant organisms [1]. In addition, mortality risk has been shown to correlate significantly and independently with Acute Physiology and Chronic Health Evaluation II score [8]. Excepting critically ill patients with short life expectancies, the detrimental effect of inadequate initial antibiotic coverage increases with increasing severity of disease [12].

Although the initial antibiotic regimen should be broad enough to cover likely pathogens, this regimen should be rapidly de-escalated after 48 to 72 hours, with subsequent antibiotic therapy determined by culture results and clinical course. In a prospective evaluation of patients with VAP [13] the use of broad initial coverage with a combination of imipenem, ciprofloxacin, and vancomycin, with modification after 24 to 48 hours, significantly increased the prevalence of adequate initial coverage $(94 \%$ versus $48 \% ; P<0.01)$, reduced the duration of therapy (9 days versus 15 days; $P<0.001$ ), and decreased recurrences ( $8 \%$ versus $24 \%$; $P=0.03$ ). A prospective randomized trial of intensive care unit patients with pulmonary infiltrates [14] evaluated the effects of a protocol of de-escalation of antibiotic therapy after 3 days, based on clinical status. This protocol resulted in a shorter duration of treatment (mean 3 days versus 10 days; $P<0.0001$ ), a lower cost of antibiotic therapy (mean \$259 versus $\$ 640 ; P<0.0001)$, and reduced prevalence of resistance and/or superinfection (15\% versus 35\%; $P=0.017$ ) compared with 'standard' therapy. However, there was no significant effect on mortality $(0 \%$ for de-escalation versus $7 \%$ for standard therapy; $P>0.05)$.

Optimal dosing is a critical component of antibiotic therapy, regardless of type or class of agent employed. In patients with serious bacterial infections, the use of maximum
Figure 2

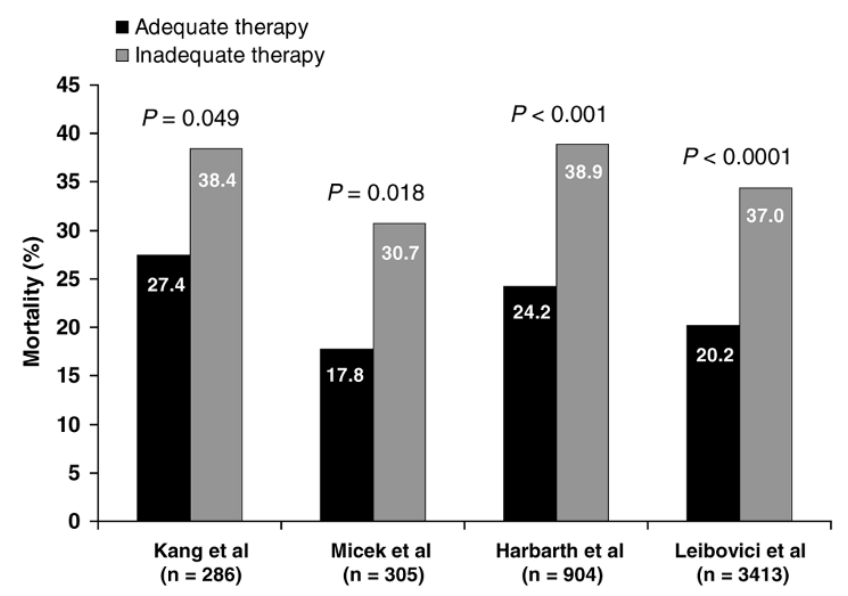

Adequate versus inadequate initial antibiotic therapy: bacteremia and severe sepsis/early septic shock. Shown is the mortality risk associated with adequate versus inadequate initial antibiotic therapy in patients with bacteremia [8-10] or severe sepsis/early septic shock [7].

tolerable antibiotic doses improves therapeutic outcomes and may prevent the development of resistance $[15,16]$. Bactericidal rather than bacteriostatic agents may be preferred, because these agents may curtail the development of resistance. As Stratton so concisely stated, 'Dead bugs don't mutate' [17]. However, even when bactericidal agents are used, the administered dose must be sufficient to achieve bactericidal activity. In a Monte Carlo simulation, the probability of achieving bactericidal activity against representative pathogens of nosocomial pneumonia (excluding methicillin-resistant Staphylococcus aureus) increased from $67.9 \%$ to $92.5 \%$ when the ceftazidime dose was doubled from 3 to $6 \mathrm{~g} /$ day, from $90.3 \%$ to $95.0 \%$ when the cefepime dose was doubled from 2 to $4 \mathrm{~g} /$ day, and from $12.0 \%$ to $54.7 \%$ when the ciprofloxacin dose was increased by $50 \%$ from 800 to $1,200 \mathrm{mg} /$ day [18]. In the same study the probability of achieving bactericidal activity for a typical carbapenem regimen was approximately $98 \%$, illustrating the potency of this class against Gram-negative infections.

Considering the therapeutic principles summarized above, this article reviews the rationale for carbapenem use in the initial therapy of serious bacterial infections that are potentially caused by Gram-negative pathogens. It also explores the potential effects of emerging resistance on carbapenem use.

\section{Carbapenem resistance mechanisms}

Activity against many multidrug-resistant (MDR) pathogens is among the main advantages of using carbapenems in patients with serious Gram-negative infections. Consequently, the future utility of carbapenems depends, to a great extent, on controlling the development of resistance to this class. 
Antibiotic resistance is a function of drug exposure and can be acquired through numerous mechanisms [19-21]. Resistance to carbapenems in particular is produced through three mechanisms: reduced permeability, efflux, and synthesis of carbapenem $\beta$-lactamases.

Reduced permeability is the major mechanism by which Pseudomonas aeruginosa acquires resistance to carbapenems in the Western hemisphere. To be effective against Gram-negative organisms, carbapenems must enter the periplasmic space. Downregulation of porin channels in the outer lipopolysaccharide membrane effectively reduces this entry. Recent data suggest that reduced permeability, in combination with certain $\beta$-lactamases, may also play a role in resistance acquisition by Klebsiella, Enterobacter, and Acinetobacter spp. [22-24].

\section{Carbapenem $\beta$-lactamases}

Synthesis of $\beta$-lactamases by Gram-negative bacilli has become increasingly important in the development of resistance to carbapenems. Four classes of $\beta$-lactamases can produce carbapenem resistance (Table 1). Traditionally, carbapenemasemediated resistance, particularly in Pseudomonas and Acinetobacter spp., was due to the synthesis of class-B metallo- $\beta$-lactamases. Although widely scattered throughout the world, bacteria possessing genes for metallo- $\beta$-lactamases have not yet penetrated North America to any great extent. Thus, carbapenems could be used with relatively little concern about $\beta$-lactamase induced resistance. However, the recent emergence of carbapenem-resistant organisms utilizing other classes of $\beta$-lactamase has altered this presumption. A chromosomal 'AmpC-like' $\beta$-lactamase that can be transferred from one organism to another via plasmids has been recognized in Klebsiella, Enterobacter, Pseudomonas, and Acinetobacter spp., which utilize this mechanism in combination with a permeability defect to create carbapenem resistance [25]. In addition, an increasing number of organisms, most notably Acinetobacter spp., can produce oxacillinase enzymes that inactivate carbapenems [26]. Finally, in 2001, Yigit and colleagues [27] reported isolation of a $K$. pneumoniae strain that possessed a novel plasmidencoded class A $\beta$-lactamase ( $K$. pneumoniae carbapenemase [KPC]-1), which conferred resistance to imipenem, meropenem, extended-spectrum cephalosporins, and aztreonam [27]. Several other KPCs have been identified since. Furthermore, this class of enzymes is no longer limited to Klebsiella but also has recently been found in Escherichia coli, Salmonella enterica, Citrobacter freundii, Serratia marcescens, and $P$. aeruginosa $[28,29]$.

\section{Emergence of resistance in $\boldsymbol{P}$. aeruginosa}

In a cohort evaluation of hospitalized patients, the likelihood of emergence of antibiotic-resistant $P$. aeruginosa was greatest in patients treated with imipenem (hazard ratio 2.8; $P=0.02$ ), followed by piperacillin (hazard ratio $1.7 ; P=0.3$ ), ciprofloxacin (hazard ratio $0.8 ; P=0.6$ ), and ceftazidime
Table 1

\begin{tabular}{ll} 
Carbapenem $\beta$-lactamases & \\
\hline$\beta$-Lactamase & Organisms \\
\hline Class A: KPC 1 to 4 & $\begin{array}{l}\text { Klebsiella, Escherichia coli, } \\
\text { Enterobacter, Salmonella, } \\
\text { Pseudomonas }\end{array}$ \\
Class B: metallo- $\beta$-lactamases & $\begin{array}{l}\text { Pseudomonas, Acinetobacter, } \\
\text { Enterobacter, E. coli, Shigella, } \\
\text { Serratia }\end{array}$ \\
Class C: AmpC-like & $\begin{array}{l}\text { Klebsiella, E. coli, Enterobacter, } \\
\text { Pseudomonas, Acinetobacter }\end{array}$ \\
Class D: oxacillinases & Pseudomonas, Acinetobacter, \\
& Enterobacter, Serratia
\end{tabular}

KPC, Klebsiella pneumoniae carbapenemase.

Table 2

\begin{tabular}{|c|c|c|}
\hline Authors (year) [ref.] & Daily dose (g) & $\begin{array}{c}\text { Treatment-emergent } \\
\text { resistance } \\
(n / \text { total [\%]) }\end{array}$ \\
\hline $\begin{array}{l}\text { Salata et al. (1985) [36] } \\
\text { Quinn et al. (1986) [38] }\end{array}$ & 1.5 to 3 & $6 / 10(60)$ \\
\hline Norrby et al. (1993) [35] & 2 & 6/19 (32) \\
\hline Cometta et al. (1994) [32] & $2^{a}$ & $14 / 21(67)$ \\
\hline Fink et al. (1994) [33] & 3 & 17/32 (53) \\
\hline Jaccard et al. (1998) [34] & 2 & $6 / 24(25)$ \\
\hline Zanetti et al. (2003) [37] & 2 & 9/27 (33) \\
\hline
\end{tabular}

aSome patients also received $150 \mathrm{mg}$ netilmicin twice a day.

(hazard ratio $0.7 ; P=0.4$ ) [30]. Similarly, in an open, prospective evaluation of intensive care unit patients, the risk for emergence of resistance was greatest in patients treated with imipenem (hazard ratio 6.0, 95\% confidence interval 2.8 to 13.2; $P<0.0001$ ), followed by piperacillin-tazobactam (hazard ratio $3.8,95 \%$ confidence interval 1.2 to $11.8 ; P=0.018$ ) and ceftazidime (hazard ratio 1.1, 95\% confidence interval 0.3 to $3.9 ; P=0.85$ ) [31]. Likewise, cumulative data from studies of patients with $P$. aeruginosa pneumonia who were treated with imipenem suggest a high rate of emergence of resistance during therapy (Table 2) [32-38]. Fear of central nervous system toxicity has caused many clinicians to limit their dosing of imipenem to $2 \mathrm{~g} /$ day, even in the presence of normal renal function. The use of maximum doses of antibiotic may limit the development of resistance, particularly that which is mediated by chromosomal mechanisms.

Decreased permeability is sufficient for the acquisition of resistance to imipenem by $P$. aeruginosa. In contrast, the acquisition of resistance to newer carbapenems requires 
both decreased permeability and increased efflux [25,39]. As a result, in vitro resistance selection occurs less frequently with newer carbapenems than with imipenem $[40,41]$. Whether this will translate into a clinically meaningful difference has not been shown.

\section{Future role of carbapenems}

The future role of carbapenems will be governed by local resistance patterns. Carbapenems are currently indicated for the initial treatment of serious infections potentially caused by MDR bacteria. They will retain this indication, whereas the prevalence of resistance due to the production of ESBLs exceeds that of resistance due to the production of KPCs and metallo- $\beta$-carbapenemases. Infections caused by ESBLproducing organisms are an increasing problem worldwide. For example, the prevalence of $K$. pneumoniae producing ESBLs has reached $50 \%$ in parts of Europe, and similar high rates have been observed in Asia and Central and South America [2]. Several groups have reported a reduction in mortality after the early initiation of carbapenem therapy for ESBL-producing organisms. In one evaluation [2] the 14-day mortality rate in patients with bacteremia caused by ESBLproducing $K$. pneumoniae was $5 \%$ in patients who received a carbapenem early, as compared with $64 \%$ in patients whose initial antibiotic regimen did not adequately cover ESBLproducing organisms.

Although ESBL-producing organisms are typically thought of as being hospital-acquired, these organisms have moved beyond the hospital setting, and their prevalence in community-acquired infections is also on the rise [42-44]. As a result, carbapenems may play an increasingly important role in the empiric emergency room treatment of serious community-acquired infections, particularly those involving the urinary and gastrointestinal tracts or in immunocompromised patients. Urinary tract infections caused by $E$. coli resistant to trimethoprim-sulfamethoxazole and fluoroquinolones are no longer uncommon [42]. In fact, a surveillance study conducted in 2006 reported a $20 \%$ rate of trimethoprim-sulfamethoxazole resistance in community-acquired urinary tract infections in North America, and many of these organisms were also resistant to cephalosporins [42].

Another potentially increased role for carbapenems is their use in combination with aminoglycosides, cefepime, polymyxins, and/or rifampin in the treatment of MDR or pan-drug resistant Gram-negative pathogens. As discussed above, reduced permeability through the outer membrane is one of the principal means by which Gram-negative pathogens acquire resistance to carbapenems. Polymyxins increase outer membrane permeability in these organisms, enhancing carbapenem penetration [45], but their use clinically still awaits controlled clinical studies. Numerous studies have demonstrated the in vitro and clinical efficacy of combination therapy against MDR pathogens, although some organisms were not susceptible to the drugs when tested individually
(Table 3) [45-48]. For example, Yoon and colleagues [45] evaluated eight isolates of Acinetobacter baumannii that were resistant to imipenem alone. However, the combination of imipenem with subinhibitory concentrations of polymyxin $B$ was bactericidal against seven of these isolates. The combination of imipenem with polymyxin B and rifampin was bactericidal against all eight isolates within 24 hours (Figure 3) [45].

Furthermore, when the infecting organism is susceptible to the antibiotic(s) being administered, adding an additional agent may improve efficacy. In a randomized evaluation of 121 patients with bacteremia due to $P$. aeruginosa that was susceptible to $\beta$-lactams and aminoglycosides [46], the addition of rifampin to standard $\beta$-lactam plus aminoglycoside therapy was associated with improvement in bacteriologic cure rate compared with standard therapy $(P=0.018)$. The potential beneficial effect of combination therapy may depend on the prevalent mechanisms of resistance. For example, adding polymyxin to carbapenem therapy should have a positive effect against resistant Gram-negative pathogens when the carbapenem resistance mechanism is reduced permeability. This may not occur if the resistance mechanism is carbapenemase production $[45,49]$. However, there are no clinical data demonstrating that adding polymyxin to carbapenem therapy has a positive effect. Suboptimal dosing is a contributing factor to poor outcomes and the emergence of resistance. Thus, antibiotics used in combination should not be administered in reduced doses.

Finally, the future development of $\beta$-lactamase inhibitors and/or efflux inhibitors may enhance and extend the utility of the carbapenem class. Both Gram-positive and Gramnegative organisms can express multidrug efflux pumps, and almost all antibiotics are susceptible to the effects of these pumps [50]. When they are used in combination with antimicrobial agents, inhibitors of these pumps should reverse resistance, enhancing the potency and expanding the spectrum of activity of antimicrobial agents while decreasing the emergence of new resistance [50]. The development of clinically useful efflux inhibitors has proven to be problematic. However, one candidate (MP-601,205; Mpex Pharmaceuticals, San Diego, CA, USA) is undergoing phase I clinical trials for the treatment of $P$. aeruginosa infections [50]. Likewise, the development of inhibitors of $\mathrm{AmpC}, \mathrm{KPC}$, or metallo- $\beta$-lactamases may extend the life span of this class, but progress has been slow [51].

\section{Target pathogens}

The majority of ESBL-producing enteric Gram-negative bacilli are susceptible to carbapenem therapy and, because of coresistance, few other good treatment options remain for many of these organisms $[2,42,52]$. In an evaluation of 312 ESBLproducing Gram-negative bacilli recovered from patients at a single urban teaching hospital [53], 75\% were found to be resistant to gentamicin, $70 \%$ to trimethoprim-sulfamethoxa- 


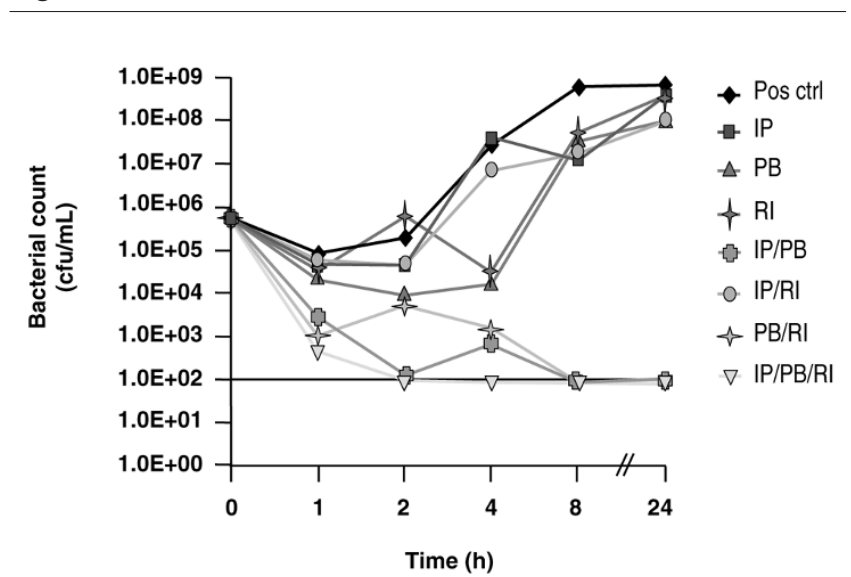

Efficacy of combination therapy against multidrug resistant Acinetobacter baumannii. cfu, colony forming units; Ctrl, control; IP, imipenem; PB, polymyxin B; Pos, positive; RI, rifampin. Adapted with permission [45]. Copyright (C 2004 American Society for Microbiology.

zole, $59 \%$ to ciprofloxacin, $40 \%$ to piperacillin-tazobactam, $11 \%$ to amikacin, and $0 \%$ to imipenem. Likewise, in an evaluation of 34 isolates of piperacillin-resistant $P$. aeruginosa recovered from patients with VAP [21], 94\% were also resistant to ticarcillin-clavulanic acid, $91 \%$ to ticarcillin, $88 \%$ to piperacillin-tazobactam, $71 \%$ to ciprofloxacin, $62 \%$ to ceftazidime, $59 \%$ to imipenem, and $50 \%$ to amikacin. Because co-resistances will vary among institutions, knowledge of the local antibiogram is crucial in selecting appropriate antimicrobial therapy for the target pathogen. Carbapenems are effective in the treatment of susceptible MDR Acinetobacter spp., with or without the addition of a second active agent [52]. They are effective in the treatment of susceptible $P$. aeruginosa when combined with a second agent [13]. When used for this indication, follow-up cultures are essential in order to detect the emergence of resistant Pseudomonas. A recent meta-analysis of 12 randomized controlled clinical trials of therapy for hospital-acquired pneumonia in immunocompetent adults [54] showed equivalence between carbapenems, fluoroquinolones, and $\beta$ lactams, alone or in combination with aminoglycosides. However, among a subset of patients with pneumonia due to $P$. aeruginosa, carbapenem therapy was associated with lower treatment success and pathogen eradication than fluoroquinolones and $\beta$-lactams.

At New York Hospital Queens, KPC-producing Klebsiella have become endemic. Thus, neutropenic patients with serious hospital-acquired infection receive a five-drug regimen to treat a wide variety of potential multiresistant pathogens. This consists of polymyxin B, vancomycin, rifampin, tigecycline, and a carbapenem. It is an aggressive protocol but, as demonstrated by Kumar and colleagues [55], time to the initiation of effective antimicrobial therapy is the 
single greatest predictor of survival in patients who develop septic shock. In their study, a 1-hour delay in the initiation of effective antibiotic therapy significantly increased in-hospital mortality risk compared with initiation of such therapy within the first hour (odds ratio 1.67, 95\% confidence interval 1.12 to 2.48 ). Furthermore, this mortality risk continued to increase for each additional hour of delay. During the initial 6-hour period, overall survival fell by $7.6 \%$ for every hour that the initiation of effective antibiotic therapy was delayed. Our aggressive protocol is continuously updated as local susceptibility patterns change. As yet, there are no controlled clinical trial data to show that our current regimen is more effective than others.

\section{Conclusion}

Achieving optimal results against serious bacterial infections requires immediate, intensive antimicrobial therapy. Early treatment should employ potent broad-spectrum agents in order to increase the probability that this initial therapy will be appropriate for the infecting pathogen. Carbapenems, often in combination with other agents, remain a mainstay of this early therapy in patients with serious hospital-acquired infection. Further evolution of community-acquired ESBLproducing organisms may broaden this indication to include initial emergency room treatment of selected serious infections. Initial empiric therapy should be re-evaluated and adjusted once data from bacteriologic studies become available. De-escalation to narrow-spectrum agents and the use of short-course therapy, if appropriate for the infecting pathogen, may help to limit the emergence of resistance. However, short-term therapy should not be used against nonfermenters such as $P$. aeruginosa. Finally, the pharmacodynamics of antibiotics employed should always be considered in order to achieve maximum dosing and the best possible outcome. Such strategies may prolong the useful life span of this valuable class of antibiotics.

\section{Competing interests}

James J Rahal receives grant and/or research support from Ortho McNeil, Wyeth, and Hemispherx Biopharma.

\section{Acknowledgements}

The author acknowledges the assistance of Phase Five Communications Inc. in the preparation of this manuscript. This work was supported by Johnson \& Johnson.

This article is published as part of Critical Care Volume 12 Supplement 4 , 2008: Optimizing the use of carbapenems in the face of increasing Gram-negative resistance. The full contents of the supplement are available online at http://ccforum.com/supplements/12/S4

Publication of this supplement has been sponsored by Ortho-McNeil, Inc.

\section{References}

1. Lee SY, Kotapati S, Kuti JL, Nightingale CH, Nicolau DP: Impact of extended-spectrum beta-lactamase-producing Escherichia coli and Klebsiella species on clinical outcomes and hospital costs: a matched cohort study. Infect Control Hosp Epidemiol 2006, 27:1226-1232.

2. Paterson DL, Ko WC, Von GA, Mohapatra S, Casellas JM,
Goossens H, Mulazimoglu L, Trenholme G, Klugman KP, Bonomo RA, Rice LB, Wagener MM, McCormack JG, Yu VL: Antibiotic therapy for Klebsiella pneumoniae bacteremia: implications of production of extended-spectrum beta-lactamases. Clin Infect Dis 2004, 39:31-37.

3. Alvarez-Lerma F: Modification of empiric antibiotic treatment in patients with pneumonia acquired in the intensive care unit. ICU-Acquired Pneumonia Study Group. Intensive Care Med 1996, 22:387-394.

4. Clec'h C, Timsit JF, De Lassence A, Azoulay E, Alberti C, Garrouste-Org, Mourvilier B, Troche G, Tafflet M, Tuil O, Cohen Y: Efficacy of adequate early antibiotic therapy in ventilatorassociated pneumonia: influence of disease severity. Intensive Care Med 2004, 30:1327-1333.

5. Luna CM, Vujacich P, Niederman MS, Vay C, Gherardi C, Matera J, Jolly EC: Impact of BAL data on the therapy and outcome of ventilator-associated pneumonia. Chest 1997, 111:676-685.

6. Rello J, Gallego M, Mariscal D, Sonora R, Valles J: The value of routine microbial investigation in ventilator-associated pneumonia. Am J Respir Crit Care Med 1997, 156:196-200.

7. Harbarth S, Garbino J, Pugin J, Romand JA, Lew D, Pittet D: Inappropriate initial antimicrobial therapy and its effect on survival in a clinical trial of immunomodulating therapy for severe sepsis. Am J Med 2003, 115:529-535.

8. Kang $\mathrm{Cl}$, Kim SH, Park WB, Lee KD, Kim HB, Kim EC, Oh MD Choe KW: Bloodstream infections caused by antibiotic-resistant gram-negative bacilli: risk factors for mortality and impact of inappropriate initial antimicrobial therapy on outcome. Antimicrob Agents Chemother 2005, 49:760-766.

9. Leibovici L, Shraga I, Drucker M, Konigsberger H, Samra Z, Pitlik SD: The benefit of appropriate empirical antibiotic treatment in patients with bloodstream infection. $J$ Intern Med 1998, 244: 379-386.

10. Micek ST, Lloyd AE, Ritchie DJ, Reichley RM, Fraser VJ, Kollef $\mathrm{MH}$ : Pseudomonas aeruginosa bloodstream infection: importance of appropriate initial antimicrobial treatment. Antimicrob Agents Chemother 2005, 49:1306-1311.

11. Kollef $\mathrm{MH}$, Ward $\mathrm{S}$ : The influence of mini-BAL cultures on patient outcomes: implications for the antibiotic management of ventilator-associated pneumonia. Chest 1998, 113:412420.

12. Harbarth S, Nobre V, Pittet D: Does antibiotic selection impact patient outcome? Clin Infect Dis 2007, 44:87-93.

13. Ibrahim EH, Ward S, Sherman G, Schaiff R, Fraser VJ, Kollef MH: Experience with a clinical guideline for the treatment of ventilator-associated pneumonia. Crit Care Med 2001, 29:1109-1115.

14. Singh N, Rogers P, Atwood CW, Wagener MM, Yu VL: Shortcourse empiric antibiotic therapy for patients with pulmonary infiltrates in the intensive care unit. A proposed solution for indiscriminate antibiotic prescription. Am J Respir Crit Care Med 2000, 162:505-511.

15. Ambrose PG, Bhavnani SM, Rubino CM, Louie A, Gumbo T, Forrest A, Drusano GL: Pharmacokinetics-pharmacodynamics of antimicrobial therapy: it's not just for mice anymore. Clin Infect Dis 2007, 44:79-86.

16. Drlica $\mathrm{K}$, Zhao $\mathrm{X}$ : Mutant selection window hypothesis updated. Clin Infect Dis 2007, 44:681-688.

17. Stratton CW: Dead bugs don't mutate: susceptibility issues in the emergence of bacterial resistance. Emerg Infect Dis 2003, 9:10-16.

18. Sun HK, Kuti JL, Nicolau DP: Pharmacodynamics of antimicrobials for the empirical treatment of nosocomial pneumonia: a report from the OPTAMA Program. Crit Care Med 2005, 33: 2222-2227.

19. DeRyke CA, Maglio D, Nicolau DP: Defining the need for new antimicrobials: clinical and economic implications of resistance in the hospitalised patient. Expert Opin Pharmacother 2005, 6:873-889.

20. Niederman MS: Is 'crop rotation' of antibiotics the solution to a 'resistant' problem in the ICU? Am J Respir Crit Care Med 1997, 156:1029-1031.

21. Trouillet JL, Vuagnat A, Combes A, Kassis N, Chastre J, Gibert C: Pseudomonas aeruginosa ventilator-associated pneumonia: comparison of episodes due to piperacillin-resistant versus piperacillin-susceptible organisms. Clin Infect Dis 2002, 34: 1047-1054.

22. Clark RB: Imipenem resistance among Acinetobacter bau- 
mannii: association with reduced expression of a 33-36 kDa outer membrane protein. J Antimicrob Chemother 1996, 38: 245-251.

23. Martinez-Martinez L, Pascual A, Hernandez-Alles S, Alvarez-Diaz D, Suarez Al, Tran J, Benedi VJ, Jacoby GA: Roles of beta-lactamases and porins in activities of carbapenems and cephalosporins against Klebsiella pneumoniae. Antimicrob Agents Chemother 1999, 43:1669-1673.

24. Yigit $\mathrm{H}$, Anderson GJ, Biddle JW, Steward CD, Rasheed JK, Valera LL, McGowan JE Jr, Tenover FC: Carbapenem resistance in a clinical isolate of Enterobacter aerogenes is associated with decreased expression of $\mathrm{OmpF}$ and $\mathrm{OmpC}$ porin analogs. Antimicrob Agents Chemother 2002, 46:3817-3822.

25. Livermore DM, Woodford N: The beta-lactamase threat in Enterobacteriaceae, Pseudomonas and Acinetobacter. Trends Microbiol 2006, 14:413-420.

26. Fzal-Shah M, Woodford N, Livermore DM: Characterization of OXA-25, OXA-26, and OXA-27, molecular class D beta-lactamases associated with carbapenem resistance in clinical isolates of Acinetobacter baumannii. Antimicrob Agents Chemother 2001, 45:583-588.

27. Yigit $H$, Queenan AM, Anderson GJ, Domenech-Sanchez A Biddle JW, Steward CD, Alberti S, Bush K, Tenover FC: Novel carbapenem-hydrolyzing beta-lactamase, KPC-1, from a carbapenem-resistant strain of Klebsiella pneumoniae. Antimicrob Agents Chemother 2001, 45:1151-1161.

28. Bratu S, Brooks S, Burney S, Kochar S, Gupta J, Landman D, Quale J: Detection and spread of Escherichia coli possessing the plasmid-borne carbapenemase KPC-2 in Brooklyn, New York. Clin Infect Dis 2007, 44:972-975.

29. Villegas MV, Lolans K, Correa A, Kattan JN, Lopez JA, Quinn JP: First identification of Pseudomonas aeruginosa isolates producing a KPC-type carbapenem-hydrolyzing beta-lactamase. Antimicrob Agents Chemother 2007, 54:1553-1555.

30. Carmeli Y, Troillet N, Eliopoulos GM, Samore MH: Emergence of antibiotic-resistant Pseudomonas aeruginosa: comparison of risks associated with different antipseudomonal agents. Antimicrob Agents Chemother 1999, 43:1379-1382.

31. Georges B, Conil JM, Dubouix A Archambaud M, Bonnet E, Saivin S Lauwers-Cances V, Cristini C, Cougot P, Decun JF, Mathe O, Chabanon G, Marty N, Seguin T, Houin G: Risk of emergence of Pseudomonas aeruginosa resistance to betalactam antibiotics in intensive care units. Crit Care Med 2006, 34:1636-1641.

32. Cometta A, Baumgartner JD, Lew D, Zimmerli W, Pittet D, Chopart P, Schaad U, Herter C, Eggimann P, Huber O, et al:: Prospective randomized comparison of imipenem monotherapy with imipenem plus netilmicin for treatment of severe infections in nonneutropenic patients. Antimicrob Agents Chemother 1994, 38:1309-1313.

33. Fink MP, Snydman DR, Niederman MS, Leeper KV, Jr., Johnson $\mathrm{RH}$, Heard SO, Wunderink RG, Caldwell JW, Schentag JJ, Siami $\mathrm{GA}$, et al.: Treatment of severe pneumonia in hospitalized patients: results of a multicenter, randomized, double-blind trial comparing intravenous ciprofloxacin with imipenemcilastatin. The Severe Pneumonia Study Group. Antimicrob Agents Chemother 1994, 38:547-557.

34. Jaccard C, Troillet N, Harbarth S, Zanetti G, Aymon D, Schneider R, Chiolero R, Ricou B, Romand J, Huber O, Ambrosetti P, Praz G, Lew D, Bille J, Glauser MP, Cometta A: Prospective randomized comparison of imipenem-cilastatin and piperacillintazobactam in nosocomial pneumonia or peritonitis. Antimicrob Agents Chemother 1998, 42:2966-2972.

35. Norrby SR, Finch RG, Glauser M: Monotherapy in serious hospital-acquired infections: a clinical trial of ceftazidime versus imipenem/cilastatin. European Study Group. J Antimicrob Chemother 1993, 31:927-937.

36. Salata RA, Gebhart RL, Palmer DL, Wade BH, Scheld WM, Groschel DH, Wenzel RP, Mandell GL, Duma RJ: Pneumonia treated with imipenem/cilastatin. Am J Med 1985, 78:104109.

37. Zanetti G, Bally F, Greub G, Garbino J, Kinge T, Lew D, Romand JA, Bille J, Aymon D, Stratchounski L, Krawczyk L, Rubinstein E, Schaller MD, Chiolero R, Glauser MP, Cometta A; Cefepime Study Group: Cefepime versus imipenem-cilastatin for treatment of nosocomial pneumonia in intensive care unit patients: a multicenter, evaluator-blind, prospective, random- ized study. Antimicrob Agents Chemother 2003, 47:3442-3447.

38. Quinn JP, Dudek EJ, DiVincenzo CA, Lucks DA, Lerner SA: Emergence of resistance to imipenem during therapy for Pseudomonas aeruginosa infections. J Infect Dis 1986, 154: 289-294.

39. Livermore DM: Of Pseudomonas, porins, pumps and carbapenems. J Antimicrob Chemother 2001, 47:247-250.

40. Sakyo S, Tomita H, Tanimoto K, Fujimoto S, Ike Y: Potency of carbapenems for the prevention of carbapenem-resistant mutants of Pseudomonas aeruginosa. The high potency of a new carbapenem doripenem. J Antibiot 2006, 59:220-228.

41. Mushtaq $S$, Ge $Y$, Livermore DM: Doripenem versus Pseudomonas aeruginosa in vitro: activity against characterized isolates, mutants, and transconjugants and resistance selection potential. Antimicrob Agents Chemother 2004, 48: 3086-3092.

42. Paterson DL, Bonomo RA: Extended-spectrum beta-lactamases: a clinical update. Clin Microbiol Rev 2005, 18:657-686.

43. Rodrígues-Baño J, Navarro M, Romero L, Muniain M, do Cuoto M, Rios M, Hernández J, Pascual A: Bacteremia due to extendedspectrum $\beta$-lactamase-producing Escherichia coli in the CTXM era: a new clinical challenge. Clin Infect Dis 2006, 43:14071414.

44. Helfand M, Bonomo R: Extended-spectrum $\beta$-lactamases in multi-drug resistant Escherichia coli: changing the therapy for hospital-acquired and community-acquired infections. Clin Infect Dis 2006, 43:1415-1416.

45. Yoon J, Urban C, Terzian C, Mariano N, Rahal JJ: In vitro double and triple synergistic activities of polymyxin B, imipenem, and rifampin against multidrug-resistant Acinetobacter baumannii. Antimicrob Agents Chemother 2004, 48:753-757.

46. Korvick JA, Peacock JE Jr, Muder RR, Wheeler RR, Yu VL: Addition of rifampin to combination antibiotic therapy for Pseudomonas aeruginosa bacteremia: prospective trial using the Zelen protocol. Antimicrob Agents Chemother 1992, 36: 620-625.

47. Ostenson RC, Fields BT, Nolan CM: Polymyxin B and rifampin: new regimen for multiresistant Serratia marcescens infections. Antimicrob Agents Chemother 1977; 12:655-659.

48. Zuravleff JJ, Yu VL, Yee RB: Ticarcillin-tobramycin-rifampin: in vitro synergy of the triplet combination against Pseudomonas aeruginosa. J Lab Clin Med 1983, 101:896-902.

49. Wareham DW, Bean DC: In-vitro activity of polymyxin B in combination with imipenem, rifampicin and azithromycin versus multidrug resistant strains of Acinetobacter baumannii producing OXA-23 carbapenemases. Ann Clin Microbiol Antimicrob 2006, 5:10-14.

50. Lomovskaya O, Bostian KA: Practical applications and feasibility of efflux pump inhibitors in the clinic: a vision for applied use. Biochem Pharmaco/ 2006, 71:910-918.

51. Livermore DM: The impact of carbapenemases on antimicrobial development and therapy. Curr Opin Investig Drugs 2002, 3:218-224.

52. Rodloff AC, Goldstein EJ, Torres A: Two decades of imipenem therapy. J Antimicrob Chemother 2006, 58:916-929.

53. Schwaber MJ, Navon-Venezia S, Schwartz D, Carmeli Y: High levels of antimicrobial coresistance among extended-spectrum-beta-lactamase-producing Enterobacteriaceae. Antimicrob Agents Chemother 2005, 49:2137-2139.

54. Siempos KZ II, Vardakas Z, Manta KG, Falagas ME: Carbapenems for the treatment of immunocompetent adult patients with nosocomial pneumonia. Eur Respir J 2007, 29:548-560.

55. Kumar A, Roberts D, Wood KE, Light B, Parrillo JE, Sharma S, Suppes R, Feinstein D, Zanotti S, Taiberg L, Gurka D, Kumar A Cheang M: Duration of hypotension before initiation of effective antimicrobial therapy is the critical determinant of survival in human septic shock. Crit Care Med 2006, 34: 1589-1596. 